\title{
DAYA HAMBAT LARUTAN BAKING SODA KONSENTRASI 70\% TERHADAP BAKTERI STREPTOCOCCUS MUTANS (IN VITRO)
}

\author{
Sri Hidayati', Jahja²,Ida Chairanna $\mathbf{M}^{3}$ \\ Email : srihidayati@gmail.com
}

\begin{abstract}
ABSTRAK
Baking soda memiliki sifat alkali yang dapat menetralkan $\mathrm{pH}$ rongga mulut sehingga dapat menghambat proses metabolisme bakteri yang menghasilkan asam. Selain itu memiliki kemampuan mempengaruhi tekanan osmotik. Sifat hipertonik dari baking soda menyebabkan hipotonik sel bakteri kehilangan air, sehingga sel akan dehidrasi dan akhirnya dapat membunuh sel bakteri. Penelitian ini bertujuan untuk mengetahui daya hambat larutan baking soda konsentrasi $70 \%$ terhadap bakteri Streptococcus mutans (In vitro, merupakan penelitian eksperimental murni kelompok perlakuan dan control group design. Pembuatan larutan baking soda $70 \%$ dan bakteri Streptococcus mutans diperoleh di Research Center Fakultas Kedokteran Gigi Universitas Airlangga. Paper disk yang berisi baking soda $70 \%$ dimasukkan oven sampai kering, control(+) Chlorhexedine 0,2\% dan control(-) Aquades diinkubasi $37^{\circ} \mathrm{C}$ selama 24 jam, zona yang terbentuk disekeliling paper disk diukur diameternya dalam $\mathrm{mm}$. Data dikumpulkan dilakukan uji normalitas dan di cari rata-rata serta SD, dianalisa menggunakan uji $\mathrm{T}$ independen. Hasil penelitian terlihat rata-rata diameter zona bening menunjukkan daya hambatnya masih belum melebihi kelompok kontrol positif dimana rata-rata kelompok perlakuan 14,21 mm sedang kelompok kontrol angka rata-rata 19,42mm. Berdasarkan hasil penelitian ini disimpulkan ada perbedaan daya hambat yang terbentuk pada lempeng agar perbenihan streptococcus mutans. Diharapkan bisa dimanfaatkan sebagai bahan antibakteri untuk mencegah karies gigi dengan pemakaian baking soda yang murah,mudah didapatkan oleh masyarakat, baik berupa kumur-kumur dan diolesan ke permukaan gigi, maupun sebagai bahan tambahan dalam pasta gigi.
\end{abstract}

Kata kunci : Bakingsoda $70 \%$, streptococcus mutans 


\section{PENDAHULUAN}

Kesehatan gigi dan mulut merupakan faktor yang sangat penting untuk diperhatikan. Bila kesehatan gigi dan mulut diabaikan bisa menimbulkan masalah baik pada gigi dan mulut itu sendiri maupun kesehatan tubuh secara umum. Salah satu bentuk kerusakan gigi adalah karies gigi. Karies gigi atau gigi berlubang merupakan penyakit gigi terlokalisir yang merusak jaringan keras gigi yang terjadi karena adanya interaksi dari beberapa faktor, yaitu host (gigi), bakteri, substrat (diet), dan waktu. Karies disebabkan karena terabaikannya kebersihan rongga mulut sehingga terjadi penumpukan plak. Plak adalah lapisan tipis yang melekat erat dipermukaan gigi serta mengandung kumpulan bakteri (Beighton, 2007).

Di Indonesia terjadi peningkatan prevalensi terjadinya karies aktif pada penduduk Indonesia dibandingkan tahun 2007 lalu, yaitu dari 43,4 \% (2007) menjadi 53,2 \% (2013) yaitu kurang lebih di Indonesia terdapat 93.998.727 jiwa yang menderita karies gigi. Suatu peningkatan yang cukup tinggi jika dilihat dari kacamata besaran kesehatan masyarakat. Terlebih jika kita konversikan ke dalam jumlah absolut penduduk Indonesia. Data estimasi olahan Pusat Data Informasi (Pusdatin) tentang penduduk usia 15 tahun ke atas sebesar 176.689.336 jiwa. Dari sejumlah itu jika hasil Riset Kesehatan (RISKESDAS) 2013 menunjukkan prevalensi 53,2 \% mengalami karies aktif (= karies yg belum ditangani atau belum dilakukan penambalan / Decay (D) > 0 tertangani), maka di Indonesia terdapat 93.998.727 jiwa yang menderita karies aktif (RISKESDAS., 2013).

Penyakit ini tersebar di seluruh dunia dan berdampak menimbulkan gangguan pada tubuh, seperti gangguan fungsi pengunyahan, penyerapan makanan, dan pencernaan. Selain itu juga dapat bermanifestasi menjadi penyakit sistemik karena gigi yang berlubang dapat menjadi sumber infeksi. Bakteri yang berperan penting dalam pembentukan plak adalah bakteri yang mampu membentuk polisakarida ekstraseluler, yaitu bakteri dari genus Streptococcus. Proses karies ditandai dengan terjadinya demineralisasi pada jaringan keras gigi, diikuti dengan kerusakan bahan organiknya. Koloni Streptococcus mutans memfermentasi sukrosa menjadi asam. Asam yang dihasilkan dapat mempercepat pemasakan plak yang berakibat pada turunnya $\mathrm{pH}$ permukaan gigi. Apabila $\mathrm{pH}$ tersebut terus turun hingga angka kritis $(5,2-$ $5,5)$, maka email gigi akan larut dan timbullah karies gigi. Hal ini akan menyebabkan terjadinya invasi bakteri dan kerusakan jaringan pulpa serta penyebaran ke jaringan periapikal dan menimbulkan rasa sakit atau nyeri (Marsh, 2005).

Streptococcus mutans merupakan bakteri gram positif, bersifat nonmotil, dan anaerob fakultatif yang dapat memetabolisme karbohidrat (Fani dkk., 2007). Streptococcus mutans pertama kali diisolasi dari plak gigi oleh Clark pada tahun 1924. Clark menyatakan bahwa bakteri Streptococcus mutans merupakan bakteri utama penyebab terjadinya karies (McCracken \& Cawson, 1983). Tumbuhan obat merupakan sumber bahan obat tradisional yang banyak digunakan secara turun-temurun. Pemanfaatan bahan alam dapat dipilih sebagai salah satu alternatif pencegahan karies gigi. Bahan alam dimanfaatkan karena sejak dahulu masyarakat sudah mempercayai bahan-bahan alam yang mampu menyembuhkan berbagai macam penyakit. Selain itu, bahan alami herbal menjadi pilihan alternatif karena mudah didapat, harga relatif murah, dan jarang menimbulkan efek samping dibandingkan obat-obatan yang dibuat dari bahan sintetis (Fauzi, 2008).

Beberapa tahun belakangan ini, baking soda atau sodium bicarbonate telah digunakan sebagai bahan antibakteri dalam pasta gigi dan bahan kumur. Keuntungan penggunaan baking soda adalah harganya murah, abrasivitas rendah, antibakteri (Paramita, D., 2015).

Salah satu komponen antibakteri yang umumnya terdapat dihampir semua pasta gigi adalah baking soda. Baking soda (Sodium Bikarbonat) merupakan komponen abrasif pada pasta gigi yang berfungsi menghilangkan plak dan stain gigi. Baking soda memiliki sifat alkali yang dapat menetralkan $\mathrm{pH}$ rongga mulut sehingga dapat menghambat proses metabolisme bakteri yang menghasilkan asam. Selain itu baking soda juga memiliki kemampuan mempengaruhi tekanan osmotik. Sifat hipertonik dari baking soda menyebabkan komponen 
hipotonik sel bakteri kehilangan air, sehingga sel akan dehidrasi dan akhirnya dapat membunuh sel bakteri. (Strassler, HE, 2013)

Penelitian yang dilakukan oleh Silhacek dan Taake pada tahun 2005 di Nebraska yang menguji pengaruh sodium bikarbonat dan hidrogen peroksida terhadap pertumbuhan bakteri Streptococcus.mutans dan dianalisis dengan spektrophotometer, 15 menunjukkan bahwa sodium bikarbonat dan hidrogen peroksida memiliki efek antibakteri terhadap pertumbuhan bakteri Streptococcus mutans. (Silhacek,2004))

Berdasarkan hal tersebut diatas maka peneliti tertarik untuk meneliti mengenai daya hambat larutan baking soda konsentrasi $70 \%$ terhadap bakteri Streptococcus mutans (In vitro)

Berdasarkan masalah diatas, maka dapat dijelaskan masalah sebagai berikut : bahwa bakteri streptococcus mutans yang terdapat dalam plak pada gigi dapat menyebabkan karies pada gigi

\section{BAHAN DAN METODE}

Penelitian ini merupakan penelitian eksperimental murni berupa kelompok perlakuan dan control group design dalam bentuk in vitro.

Rancangan penelitian sebagai berikut :

$$
\begin{aligned}
& \mathrm{E} 1: \mathrm{O} 1 \longrightarrow \mathrm{O} 2(\text { perlakuan }) \\
& \mathrm{E} 2: \mathrm{O} 1 \longrightarrow \mathrm{O} 2(\text { Kontrol }+) \\
& \mathrm{E} 3: \mathrm{O} 1 \longrightarrow \mathrm{O} 2(\text { Kontrol }-)
\end{aligned}
$$

Penelitian ini akan dlakuan untuk pembuatan larutan baking soda $70 \%$ dan bakteri Streptococcus mutans diperoleh di Research Center Fakultas Kedokteran Gigi Universitas Airlangga Surabaya Kementrian Riset, Teknologi dan Pendidikan Tinggi.

Waktu penelitian diperkirakan penelitian diperkirakan penelitian diperkirakan 4 bulan mulai bulan Juni sampai dengan bulan September 2018

Besar sampel penelitian ditentukan dengan menggunakan rumus Federer (1977)yaitu: (t-1)(r-1) $\geq 15$ Pada penelitian ini kelompok perlakuan adalah konsentrasi pelarut dengan konsentrasi

$70 \%$. Untuk kontrol positif digunakan Chlorhexedine 0,2\% dan untuk kontrol negatif digunakan aquades. Alat yang digunakan dalam penelitian ini adalah cawan petri, tabung reaksi, rak tabung reaksi, gelas ukur, kapas lidi steril, lampu spiritus, labu erlenmeyer, pinset, pipet tetes, jarum ose, kertas cakram berdiameter $6 \mathrm{~mm}$, kertas label, kertas saring, plat silica gel CF254, penangas air, megnetic stirrer, shaker, soxhlet, inkubator, jangka sorong dengan ketelitian $0,05 \mathrm{~mm}$, timbangan analitik, autoklaf, kromatografi cair vakum (KCV). Bahan yang digunakan adalah bakteri Streptococcus mutans isolate lapangan, Baking soda dengan konsentrasi 70\%, aquades, blood agar plate ditambah dengan darah kelinci, pelarut $\mathrm{N}$ - heksan, etilasetat, alcohol 70\%, paper disk, Chlorhexedine 0,2\%, bakteri Streptococcus mutans, pelarut dimetilsulfoksida (DMSO) dan H2SO4.

1. Penelitian dilakukan di research center Fakultas Kedokteran Gigi Universitas Airlangga Surabaya Kementrian Riset Teknologi dan Pendidikan Tinggi untuk membuat larutan baking soda sesuai dengan konsentrasi yang diinginkan yaitu konsentrasi $70 \%$.

2. Paper disk kosong (bangko) dicelup kedalam larutan baking soda $70 \%$ sampai jenuh kemudian paper diski diangkat dan dikeringkan di oven sampai kering.

3. Streptococcus mutans ditanam di blood Agar plate diinkubasi pada $37^{\circ} \mathrm{C}$ selama 24 jam untuk diuji sifat2nya .Streptococcus mutans dibuat suspense dalam $\mathrm{NaCl}$ fisiologis dengan konsentrasi $10^{3} \mathrm{cfu} / \mathrm{ml}, 0,2 \mathrm{ml}$ suspense bakteri diratakan dipermukaan BA plate, ditunggu \pm 15 detik 
4. Paper disk yang sudah berisi baking soda $70 \%$ diangkat dan dimasukkan dalam oven sampai kering, control (+) Chlorhexedine $0,2 \%$ dan control (-) Aquades diinkubasi $37^{\circ} \mathrm{C}$ selama 24 jam

5. Zona yang terbentuk disekeliling paper disk diukur diameternya dalam $\mathrm{mm}$ dan dibandingkan dengan control (+) dan control (-)

Data dikumpulkan dilakukan uji normalitas dulu dan di cari mean ( rata-rata) serta SD ( standar deviasi) baru dianalisa dengan menggunakan uji T sampel independen.

\section{HASIL DAN PEMBAHASAN}

Hasil dari penelitian yang dilakukan di Research Center Fakultas Kedokteran Gigi Universitas Airlangga Surabaya Kementrian Riset Teknologi dan Pendidikan Tinggi RI. Dapat dilihat dari tabel dibawah ini :

Tabel 4.1. Pengukuran zona hambat $(\mathrm{mm})$

\begin{tabular}{|c|c|c|c|}
\hline $\begin{array}{l}\mathrm{N} \\
\mathrm{O}\end{array}$ & $\begin{array}{c}\text { CHLORHE } \\
\text { XIDINE0,2 } \\
\% \\
\text { (control +) }\end{array}$ & $\begin{array}{l}\text { Aquades } \\
\text { (control -) }\end{array}$ & $\begin{array}{c}\text { Baking } \\
\text { soda } \\
70 \%\end{array}$ \\
\hline 1 & 19,6 & 0 & 14,2 \\
\hline 2 & 19,4 & 0 & 14,0 \\
\hline 3 & 19,55 & 0 & 14,35 \\
\hline 4 & 18,8 & 0 & 14,4 \\
\hline 5 & 19,6 & 0 & 14,2 \\
\hline 6 & 19,8 & 0 & 14,4 \\
\hline 7 & 19,2 & 0 & 13,95 \\
\hline
\end{tabular}

\section{Data primer}

Kemudian dengan menggunakan statistic diskriptif didapatkan bahwa angka rata-rata dari kelompok perlakuan dan kelompok control didapatkan hasil data dilihat dari table 4.2 sebagai berikut :

Tabel4.2. Angka Rata-rata antara kelompok perlakuan dan kontrol

\begin{tabular}{clcc}
\hline NO & Kelompok & Mean & SD \\
\hline 1 & Chlorhexedine & 19,4214 & 0,3314 \\
& $0,2 \%$ & & 8 \\
\hline 2 & $\begin{array}{l}\text { Baking soda } \\
70 \%\end{array}$ & 14,2143 & 0,1842 \\
& & & 0
\end{tabular}

Data primer

Dari tabel diatas terlihat bahwa angka rata-rata diameter dari zona bening yang menunjukkan daya hambat dari kelompok perlakuan yang menggunakan larutan baking soda konsentrasi $70 \%$ masih belum bisa menggalahkan atau melebihi kelompok kontrol positif yang menggunakan obat kumur chlorhexedine 0,2\% dimana terlihat dari angka rata kelompok perlakuan 14,21 mm sedang kelompok kontrol positif menunjukkan angka rata-rata 19,42 mm

\section{PEMBAHASAN}

Larutan bahan baking soda $70 \%$ yang dipakai sebagai bahan penelitian ini mempunyai daya hambat anti bakteri terhadap streptococcus mutans terlihat adanya zona bening disekitar perlakuan dimana ukuran zonanya masih dibawah ukurannya masih lebih kecil dari zona kelompok control. 
Hal ini sesuai dengan penelitian Ghassemi dan Vorwerk pada tahun 2008 kemampuan antibakteri dari baking soda tidak terlalu kuat hal ini disebabkan karena sifatnya yang mudah larut, selain itu baking soda juga mampu merusak struktur matriks bakteri dan juga merusak ikatan antara bakteri dan permukaan gigi. Penelitian tersebut yang membandingkan kemampuan antibakteri dari pasta gigi baking soda dan triclosan, hasil penelitian menunjukkan pasta gigi baking soda lebih efektif dalam menghambat bakteri plak.( Ghassemi,2008).

Pada bidang kedokteran gigi, efek baking soda dalam bentuk permen karet, gel, ataupun tablet pada $\mathrm{pH}$ mulut telah banyak diteliti dan membuktikan bahwa baking soda membantu kapasitas penyangga dari saliva.(Abbate. GM, 2013) Penggunaan produk-produk yang menggunakan baking soda seperti pasta gigi sangat dianjurkan karena telah terbukti efektifitas baking soda terhadap penetralan asam.(Hurlbutt $M, 2010$ ) Pada penggunan pasta gigi yang mengandung baking soda, baking soda akan menstimulasi saraf parasimpatis dari nukleus salivatori superior dan inferior pada batang otak. Nukleus akan terangsang dengan rangsangan sentuhan dan pengecapan pada lidah dan daerah mulut serta faring, sehingga meningkatkan sekresi saliva.(Tjahajawati. D, 2007) Pemberian pasta gigi yang mengandung baking soda membuat terjadinya pelepasan baking soda dalam mulut dan dalam beberapa waktu menyebabkan peningkatan kapasitas penyangga dari saliva.(Abbate. GM, 2013) Selain pasta gigi, mengkonsumsi makanan yang mengandung baking soda terbukti dapat meningkatkan pH saliva.(Rini.YW, 2009)

Baking soda dan fluor memiliki efek penghilang plak dan bersifat sebagai antibakteri. (Maldupo,2012). Fluor mempengaruhi aktifitas Streptococci yang bersifat kariogenik dengan cara menghambat produksi asam dan glucosyltransferase (Gtf). Fluor bekerja dengan cara menghambat metabolisme bakteri plak yang dapat memfermentasi karbohidrat melalui perubahan hidroksi apatit pada email menjadi fluor apatit yang lebih stabil terutama bila terpapar asam.(Santi. C, 2010)

Baking Soda (Sodium Bikarbonat) merupakan salah satu komponen abrasif yang terdapat dalam pasta gigi. Baking soda merupakan komponen abrasif pasta gigi dengan bahan dasar karbonat. Baking soda pertama kali digunakan sebagai pembersih perak pada tahun 1920. Saat ini, baking soda banyak ditambahkan ke dalam pasta gigi untuk membersihkan gigi dari plak, karena baking soda memiliki banyak sifat yang menguntungkan, diantaranya harga yang murah, aman, tingkat abrasif yang rendah, larut dalam air, sifat menetralkan asam, kompatibel dengan fluor, dan kemampuan antibakteri.(Heretren, 2013)

Berdasarkan penelitian yang dilakukan Mark dan Kimberly pada tahun 2008 di Amerika yang membandingkan efisiensi pasta gigi baking soda dan pasta gigi lain dalam membersihkan plak, memperlihatkan bahwa pasta gigi baking soda lebih efektif dalam membersihkan plak dari pasta gigi lain. Hal ini dikarenakan struktur kristal baking soda yang bersifat besar dan lembut, sehingga efektif dalam melepaskan lapisan lengket plak dari permukaan gigi dan tidak terlalu merusak permukaan gigi. .(Putt M,et all, 2008)

Baking soda merupakan salah satu bahan yang dapat mencegah karies selain fluor, karena baking soda memiliki sifat alkali atau menetralkan asam, sehingga dapat menetralkan asam yang diproduksi bakteri plak. Baking soda juga dapat menetralkan kondisi lingkungan asam bakteri rongga mulut. $\mathrm{pH}$ kritis rongga mulut adalah 4,5 sampai 5,5 . Ketika $\mathrm{pH}$ rongga mulut berada pada $\mathrm{pH}$ kritis maka email akan mengalami proses demineralisasi yang akan menyebabkan terjadinya karies. Baking soda yang memiliki sifat menetralkan akan meningkatkan $\mathrm{pH}$ rongga mulut hingga mendekati $\mathrm{pH}$ netral menyebabkan matriks email gigi akan terhindar dari demineralisasi bakteri plak (Strassle, 2013)

Faktor lain yang menyebabkan efek antibakteri baking soda adalah kemampuannya mengubah tekanan osmotik. Sifat hipertonik baking soda menyebabkan komponen hipotonik sel bakteri akan kehilangan air, sehingga menyebabkan dehidrasi dan membunuh sel. Namun dikatakan baking soda harus berinteraksi dengan sel bakteri minimal 30 menit agar dapat efektif membunuh sel bakteri.(Silhacek,2004) 
Baking soda adalah senyawa kimia dengan rumus $\mathrm{NaHCO}$, senyawa ini disebut Natrium bikarbonat. Baking soda salah satu pembersih yang efektif, dapat digunakan untuk menghilangkan perubahan noda pada gigi. Keuntungan lain dari baking soda adalah dapat menghilangkan bau mulut dan dapat memutihkan gigi karena baking soda dapat mengurangi pertumbuhan bakteri dan membuang penumpukan plak (Paramita, D., 2015).

Baking soda atau biasa disebut dengan sodium bikarbonat . Baking soda merupakan salah satu bahan abrasif yang ditambahkan dalam pasta gigi yang berguna untuk menghilangkan noda plak, tetapi tidak mengubah warna dari gigi. Pada penggunaan baking soda sebagai obat kumur menyebabkan penurunan $\mathrm{pH}$ plak setelah 49 menit. Selain memiliki efek sebagai penghilang plak, baking soda juga dapat bersifat sebagai antibakteri (Linardi, AN., 2014).

Baking soda larut dalam air pada keadaan suhu ruangan normal (sekitar $20^{\circ} \mathrm{C}$ ). Baking soda tidak larutan dalam alkohol. Untuk penggunaan yang aman, baking soda diencerkan dalam air. Baking soda stabil di udara terbuka dan suhu kamar normal, sehingga dapat disimpan dalam tempat yang tertutup dan tidak perlu penangan khusus. Larutan kumur ini dapat dibuat dengan mencampurkan setengah sendok teh baking soda dengan 8 oz (250 ml) air (Pratama, MABP., 2014).

Pasta gigi yang mengandung baking soda. Komposisi : 70\% Sodium Bikarbonat dan ekstrak herbal (Mocamidoprophyl Betaine, Mentha Piperita Oil, Mentha Arvensis, Echinacea Purpurea, Krameria triandria, Chamomilla Recutita, Salva Officinalis, Commiphora Myrrha), air, gliserin, alkohol, Xanthan Gum, Sodium Saccharin, Cl 77491, Sodium fluor 0,22\% c. ( Linardi AN, 2014)

\section{KESIMPULAN}

Rata-rata diameter zona hambat yang terbentuk pada lempeng agar perbenihan streptococcus mutans pada kelompok kontrol positif (Chlorhexedine 0,2\%) lebih besar.

1. Rata-rata diameter zona hambat yang terbentuk pada lempeng agar perbenihan streptococcus mutans pada kelompok perlakuan (baking soda 70\%) lebih kecil.

2. Rata-rata diameter zona hambat yang terbentuk pada lempeng agar perbenihan streptococcus mutans pada kelompok kontrol negatif (aquades) tidak ada.

3. Ada perbedaan daya hambat yang terbentuk pada lempeng agar perbenihan streptococcus mutans pada kelompok perlakuan dan kelompok kontrol positif

\section{DAFTAR PUSTAKA}

1. Abbate GM, Giada C, Luca L. Salivary pH after a glucose rinse : effects of a new sodium bicarbonate mucoadhesive spray. A preliminary study. ARIESDUE; 2013

2. Agtini Md, Sintawati, Tjahja I. Fluor dan kesehatan gigi. Media Litbang Kesehatan; 2005

3. Dewi A,Tjahajawati S,Wiharja R. Saliva secretion difference before and after rinsing with baking soda on menopause women. J Dent; 2007.

1. Ferjeskov O, Kidd E. Dental caries the disease and clinical management 2 nd Ed. Oxford : Blackwell Munksgard ; 2008

2. Ghassemi A, Vorwerk L, Hooper W. A Four-Week Clinical Study to Evaluate and Compare the Effectiveness of a Baking Soda Dentifrice and an Antimicrobial Dentifrice in Reducing Plaque. J Clin Dent ; 2008

3. HerefrenJ, Li Na. Dentifrice Abrasives: Heroes or Villains? Available at http://www.ineedce.com/ courses /1431/pdf/dentifriceabrasives.pdf

4. Hurlbutt M, Brian N, Young D. Dental caries: a pH-mediated disease. CDHA Journal; 2010

5. Linardi AN, Perbedaan pH saliva antara pengguna pasta gigi yang menggandung baking soda dan pengguna pasta gigi yang mengandung fluor, skripsi, Makasar Universitas Hasanudin, 2014 
6. Maldupa I, Anda B, Inga R, Anna M. Evidence base toothpaste classification, according to certain characteristics of their chemical compotition.Baltic Dental and Maxillofacial Journal; 2012.

7. Nugraha A. Streptococcus mutans si plak dimana mana. Fakultas Farmasi USD Yogyakarta ;2008

8. Putri M, Herijulianti E, Nurjannah N. Ilmu pencegahan penyakit jaringan keras dan jaringan pendukung gigi. Jakarta : EGC;2008

9. Putt $\mathrm{M}$, et all. Enhancement of plaque removal efficacy by tooth brushing with baking soda dentrifrices : results of five clinical studies. J Clin Dent ; 2008

10. Rini YW, Iskandar S, Mandojo R, Witjaksono W. Change pattern of saliva pH between low and high caries risk patient after consuming snacks containing sucrose and xylitol. DENTIKA; 2009.

11. Roslan AN, Jenny S, Anis I. Penurunan sensitivitas rasa manis akibat pemakaian pasta gigi yang mengandung sodium lauryl sulphate 5\%. Jurnal PDGI; 2009

12. Santi C, Sri R, Cut RR. Pengaruh bahan antikaries bebrapa tanaman herbal yang dikombinasikan dengan pasta gigi yang mengandung fluoride terhadap pertumbuhan streptococcus mutans secara in vitro. DENTIKA; 2010

13. Silhacek K, Taake K. Sodium bicarbonat and hidrogen peroxide the effect on the growth of streptococcus mutans. JDent Health; 2005(79) 6. Moynihan P, Petersen P. Diet,nutrition,prevention dental caries. Public Health Nutrition 2004.

14. Strassler HE. Toothpaste ingredients make difference: patient-specific recommendations. Benco Dental supervised study course. http://d3e9u3gw8odyw8.cloudfront.net/toothpaste_ingredients.pdf.

15. Tim Riset Kesehatan Dasar : Profile kesehatan di Indonesia \{internet\} Avalaible at http://www.litbang.Depkes.go.id/simnas4/day 2/gigi.pdf

16. Wang XL, Chuo YC, Dong P, Bing W, Ye HG. Dental plaque pH recovery effect of arginine bicarbobate rinse in vivo. The Chinese Journal of Dental Research; 2012

17. Zhu L,et all.Functional characterization of cell-wall-associated protein WapA in streptococcus mutans. Microbiology; 2006 